\title{
Uma Análise da Ciclicidade da Política Fiscal Brasileira
}

\author{
Sérgio Ricardo de Brito Gadelha \\ Professor - Centro de Estudos e Pesquisa em Economia e Gestão Governamental \\ Endereço para Contato: SEPN - Quadra 513, Bloco D, Ed. Imperador, $1^{\circ}$ Andar, Sala 130 \\ CEP: 70769-900 - E-mail: professor.sergio.gadelha@gmail.com
}

\author{
José Angelo Divino \\ Mestrado e Doutorado em Economia, Universidade Católica de Brasília. \\ Endereço para contato - SGAN 916, sala A-118 - Brasília - Brasil \\ CEP: 70719-160 E-mail: jangelo@pos.ucb.br
}

Recebido em 14 de agosto de 2012. Aceito em 21 de junho de 2013.

\begin{abstract}
Resumo
Uma vasta literatura teórica e empírica afirma que a política fiscal nos países em desenvolvimento é pró-cíclica, enquanto que em nações industrializadas a política fiscal é anticíclica ou acíclica. Utilizando dados mensais, macroeconômicos e fiscais, abrangendo o período de março de 2002 a julho de 2011, os resultados obtidos a partir de estimações GMM, em modelos estáticos e dinâmicos, indicam comportamento pró-cíclico da política fiscal brasileira, onde as teorias sobre variabilidade da base tributária, corrupção e economia informal contribuem para explicar esse comportamento. Todavia, a teoria sobre restrição ao crédito internacional não encontra respaldo empírico no período analisado.
\end{abstract}

\section{Palavras-Chave}

Política Fiscal Pró-Cíclica, Economia Informal, Corrupção, Fluxo de Capitais, Variabilidade da Base Tributária.

\begin{abstract}
A vast theoretical and empirical literature states that fiscal policy in developing countries is procyclical, whereas in industrialized countries fiscal policy is countercyclical or acyclical. Using fiscal and macroeconomic monthly data covering the period from March 2002 to July 2011, the results obtained from GMM estimations in static and dynamic models indicate procyclical fiscal policy in Brazil, where the theories about tax base variability, corruption, and informal economy contribute to explain this behavior.
\end{abstract}

- Sérgio Ricardo de Brito Gadelha agradece ao Programa de Pós-Graduação

Stricto Sensu em Economia da Universidade Católica de Brasília, assim como aos colegas da Coordenação-Geral de Estudos Econômico-Fiscais da STN, em particular, à CoordenadoraGeral Fabiana Magalhães Almeida Rodopoulos, por todo apoio em seu doutorado e na realização deste estudo.

José A Divino agradece ao CNPq o apoio financeiro.

Os autores agradecem a um parecerista anônimo os valiosos comentários e sugestões.

As opiniões expressas neste estudo são de exclusiva responsabilidade dos autores, não expressando necessariamente a opinião da Secretaria do Tesouro Nacional. Todos os erros remanescentes são responsabilidade exclusiva dos autores. 
However, the theory about international credit constraint does not find empirical support in the analyzed period.

\section{Keywords}

Procyclical Fiscal Policy, Informal Economy, Corruption, Capital Flows, Tax Base Variability.

\section{JEL Classification}

E26, E32, E62, F41, H30, H50

\section{Introdução}

A recente crise financeira internacional causou um impacto na estabilidade macroeconômica brasileira durante o último trimestre de 2008 e o primeiro semestre de 2009. Como resposta a essa crise, o governo brasileiro implementou uma série de medidas fiscais com o propósito de estimular a economia, tais como desonerações tributárias e aumentos de gastos governamentais. O estudo do comportamento cíclico da política fiscal brasileira é tema relevante no atual debate acadêmico, com importantes implicações de política econômica. De acordo com Ilzetzki (2011), a política fiscal anticíclica refere-se à combinação de gastos públicos anticíclicos, alíquotas tributárias pró-cíclicas ou acíclicas, e déficits orçamentários anticíclicos. Por outro lado, política fiscal pró-cíclica refere-se a um desvio de qualquer uma dessas variáveis da definição anticíclica. Isto é, por analogia, política fiscal pró-cíclica refere-se a combinação de gastos pró-cíclicos, alíquotas tributárias anticíclicas e déficits orçamentários pró-cíclicos.

Kaminski, Reinhart e Vegh (2004) definem uma política fiscal acíclica como sendo uma política em que as flutuações no produto real não têm impacto no gasto governamental discricionário e nas alíquotas tributárias, assim como definem uma política fiscal pró-cíclica como sendo uma política em que aumentos no produto real levam a aumentos discricionários nos gastos públicos e/ou corte de impostos. Dessa forma, tanto Kaminski, Reinhart e Vegh (2004) quanto Ilzetzki (2011) concordam que a política fiscal pró-cíclica contempla a ocorrência de gastos públicos pró-cíclicos.

Em nações desenvolvidas, as evidências empíricas têm indicado que a política fiscal é anticíclica (FATAS e MIHOV, 2001; LANE, 2003; GALI e PEROTTI, 2003; GALI, 2005), tendo como meta suavizar 
as flutuações cíclicas na renda e no emprego, ou ao menos, a política fiscal é acíclica. Todavia, um número de recentes contribuições encontrou evidências de política fiscal pró-cíclica em várias nações em desenvolvimento (GAVIN e PEROTTI, 1997a; TORNELL e LANE, 1999; TALVI e VEGH, 2005; ALESINA, CAMPANTE e TABELLINI, 2008; ÇIÇEK e ELGIN, 2011; ILZETZKI, 2011). No entanto, não há consenso sobre o que pode estar conduzindo esta diferença específica, entre nações industrializadas e países em desenvolvimento, no tocante ao caráter cíclico da política fiscal, tornandose assim um enigma em busca de uma explicação.

As políticas fiscais pró-cíclicas são o resultado de políticas macroeconômicas malconduzidas ou de circunstâncias específicas em que esses países operam? Entender essas questões intrigantes é um importante passo na condução de políticas econômicas nos países em desenvolvimento, e em especial para o Brasil, cuja política fiscal tem sido utilizada, nos últimos anos, como instrumento de estabilização econômica. Não é evidente, porém, como foi conduzida a política fiscal brasileira em um horizonte mais longo, que contempla o período pós-regime de metas para a inflação. Essa é uma das questões que será abordada nesse estudo.

A literatura tem apontado diversas explicações para o enigma da pró-ciclicidade da política fiscal em países em desenvolvimento, que podem ser classificadas em dois grupos (BEN SLIMANE e BEM TAHAR, 2010). O primeiro grupo se fundamenta em argumentos relacionados às imperfeições existentes no mercado de crédito internacional, em que o acesso limitado aos fundos doméstico ou internacional pode dificultar a habilidade do governo em perseguir uma política fiscal expansionista em "tempos ruins". Nesse contexto, Gavin e Perotti $(1997 a, b)$ sugerem que a política fiscal na América Latina é pró-cíclica, de modo que durante as expansões econômicas, o consumo do governo aumenta e os impostos diminuem, enquanto que o oposto é verdadeiro durante as recessões. Os governos de nações em desenvolvimento tendem a se tornar restritos ao crédito internacional em períodos de desaceleração econômica, o que pode forçá-los a incorrerem em uma política fiscal pró-cíclica, uma vez que nas recessões a escassez da oferta de crédito limita o crescimento dos gastos governamentais. 
Por sua vez, Kaminsky, Reinhart e Vegh (2004) evidenciam que, em um grupo de países em desenvolvimento, os ingressos de capitais decrescem durante tempos de recessão à medida que o gasto governamental se reduz e a taxa de juros se eleva. Em outras palavras, os fluxos de ingressos de capitais para países em desenvolvimento são prócíclicos, e esses países tendem a contrair empréstimos nos "tempos bons" e pagá-los nos "tempos ruins". Esse acesso pró-cíclico aos mercados de capitais internacionais força os países em desenvolvimento a adotar políticas fiscais pró-cíclicas, isto é, durante períodos em que a economia está em expansão, esses países tomam empréstimos com maior facilidade e aumentam gastos públicos. Todavia, a fim de evitar o acesso limitado aos mercados de capitais internacionais, em "tempos ruins", os governos devem realizar ajustamentos fiscais.

O segundo grupo baseia-se em explicações econômico-políticas e institucionais. Nesse contexto, Talvi e Vegh (2005) estudam a política fiscal ótima em um modelo à la Lucas e Stokey (1983) em que, ao se incorrer em superávit orçamentário, cria-se pressão para aumentar gasto governamental. Embora essa distorção não seja suficiente para produzir déficit orçamentário pró-cíclico ou, em outras palavras, superávit orçamentário contra-cíclico, os resultados implicam que, quando a base tributária flutua, a distorção torna o déficit orçamentário menos contra-cíclico. Dessa forma, quanto mais variável for a base tributária, menos anticíclico é o déficit orçamentário.

Alesina, Campante e Tabellini (2008) informam que um governo corrupto exibe políticas fiscais pró-cíclicas, uma vez que os eleitores, que não confiam nesse governo, demandam maior utilidade quando percebem o crescimento do produto agregado da economia. De modo específico, quando a renda aumenta, os eleitores demandam mais consumo do governo ou corte de impostos, temendo que a renda extra gerada pela expansão econômica seja desperdiçada. Usando um conjunto de dados em painel e de cross-section para 78 países, Çiçek e Elgin (2011) encontraram que a pró-ciclicidade da política fiscal é mais pronunciada em países com um maior tamanho da economia informal. Dessa forma, as políticas de redução do tamanho da economia informal levam a uma menor (maior) resposta fiscal pró-cíclica (anticíclica) aos choques. O objetivo geral desse estudo é investigar se o comportamento da política fiscal no Brasil é pró-cíclico ou anticíclico. Caso ocorra a confirmação da natureza pró-cíclica da política fiscal, serão testadas as principais teorias 
sobre pró-ciclicidade fiscal para o caso brasileiro. Essa investigação empírica contribui com a literatura porque pesquisas sobre o tema em análise ainda são escassas para o caso brasileiro, e nos estudos existentes que evidenciaram o comportamento pró-cíclico da política fiscal (ROCHA e GIUBERTI, 2008; ROCHA, 2009; MENDONÇA, MEDRADO e SACHSIDA, 2009; THOMAS, 2010), não houve uma preocupação de se testar se essas teorias podem ser usadas para explicar a pró-ciclicidade da política fiscal.

As evidências aqui obtidas a partir de estimações de modelos estáticos e dinâmicos usando o método de momentos generalizados (GMM) convergem para a constatação do comportamento pró-cíclico da política fiscal no caso brasileiro. Além disso, as teorias sobre variabilidade da base tributária (TALVI e VEGH, 2005), corrupção (ALESINA, CAMPANTE e TABELLINI, 2008) e economia informal (ÇIÇEK e ELGIN, 2011) contribuem, conjuntamente, para explicar esse comportamento fiscal. Todavia, a teoria sobre restrição ao crédito internacional (GAVIN e PEROTTI, 1997a,b; KAMINSKY, REINHART e VEGH, 2004) não encontra respaldo empírico no período analisado.

Esse artigo encontra-se dividido da seguinte forma. A próxima seção apresenta a modelagem empírica e discute a estratégia de estimação, destacando o método dos momentos generalizados e os testes de raiz unitária, com e sem quebra estrutural. A descrição e o tratamento dos dados são apresentados na terceira seção. Os resultados econométricos obtidos a partir das estimações GMM são reportados e analisados na quarta seção. A quinta seção apresentada as considerações finais.

\section{Estratégia Empírica}

\subsection{Modelo Empírico}

A Lei de Wagner (WAGNER, 1911) considera os gastos públicos como uma variável comportamental, ou seja, endógenos, postulando que o crescimento na atividade econômica causa um aumento nas atividades governamentais. A versão utilizada para medir a elasticidade do gasto governamental em relação a mudanças na renda possui a seguinte especificação (AKITOBY et al., 2006): 


$$
G_{t}=A Y_{t}^{\eta}
$$

Cuja versão log-linear é descrita por:

$\log \left(G_{t}\right)=a+\eta \log \left(Y_{t}\right)$

onde $a=\log (A), G_{t}$ é o gasto governamental total real, $Y_{t}$ é a renda nacional real ou produto interno bruto real no ano $t$ e $A$ é uma constante. O termo $\eta$ mede a elasticidade-renda de longo-prazo do gasto governamental em relação ao produto agregado. Um valor de $\eta<1$ é consistente com a interpretação expansionista da Lei de Wagner, implicando que o gasto governamental aumenta menos do que proporcionalmente à renda nacional. Por outro lado, $\eta>1$ é consistente com a interpretação restritiva defendida por Wagner (1911), de que o gasto governamental aumenta proporcionalmente mais do que o nível de renda da economia.

Akitoby et al. (2006) utilizam o arcabouço teórico da Lei de Wagner para examinar o comportamento cíclico de curto e de longo prazo do gasto governamental, sob diversas categorias de gastos, em relação ao produto agregado de 51 países em desenvolvimento no período 1970-2002, usando um modelo de correção de erros para dados em painel. Os resultados obtidos evidenciam que, em $2 / 3$ das nações na América Latina, existe uma relação de curto prazo estatisticamente significante entre choques no produto real e gasto primário real, bem como gasto e produto movem-se de maneira pró-cíclica.

Neste estudo, retoma-se a iniciativa de Akitoby et al.(2006) em analisar a natureza cíclica da política fiscal a partir da Lei de Wagner, mas considerando duas importantes modificações no modelo da equação (1). A primeira modificação consiste em dividir ambos os lados da equação (1) por $Y_{t}$ e aplicar logaritmo, de forma a obter:

$$
\log \left(\frac{G_{t}}{Y_{t}}\right)=\log (A)+(\eta-1) \log \left(Y_{t}\right) \Rightarrow g_{t}=\alpha+\phi y_{t}
$$

em que $g_{t}=\log \left(G_{t} / Y_{t}\right), \alpha=\log (A), y_{t}=\log \left(Y_{t}\right)$ e $\phi=(\eta$-1). A segunda modificação, em conformidade com Alesina, Campante e Tabellini (2008), consiste em usar o hiato do produto como proxy para o nível 
de atividade econômica ${ }^{1}$. Assim, propõe-se a estimação do seguinte modelo básico na versão estática:

$$
g_{t}=\alpha+\phi y_{t}^{c}+\kappa\left(\text { fteo }_{t}\right)+\delta z_{t}+\gamma d c r i s e_{t}+\varepsilon_{t}
$$

A versão dinâmica é representada por:

$$
g_{t}=\alpha+\beta g_{t-1}+\phi y_{t}^{c}+\kappa\left(\text { fteo }_{t}\right)+\delta z_{t}+\gamma \text { dcrise }_{t}+\varepsilon_{t}
$$

As equações (4) e (5) capturam uma função de reação fiscal, na qual o gasto governamental responde ao nível de atividade contemporâneo e outras variáveis de controle (ILZETZKI e VEGH, 2008; ALESINA, CAMPANTE e TABELLINI, 2008). O comportamento cíclico da política fiscal será determinado pela avaliação do sinal e da significância estatística da elasticidade do gasto governamental em relação ao hiato do produto $(\phi)$. Dessa forma, na política fiscal pró-cíclica, observa-se $\eta>0$, o que resulta em $\phi>-1$. Na política fiscal acíclica, tem-se que $\eta=0 \Rightarrow \phi=1$. No caso de política fiscal anticíclica, nota-se $\eta<0 \Rightarrow \phi<-1$. O termo $\alpha$ é uma constante, e $\varepsilon_{t} \sim$ i.i.d. $\left(0, \sigma^{2}\right)$ é o termo de erro aleatório.

O termo $g_{t^{-1}}$ é o gasto governamental defasado, incluído na equação (5) para permitir reversão à média de longo prazo da variável gasto/PIB, uma vez que decisões de política fiscal no período anterior podem ter efeitos duradouros no período seguinte (THORNTON, 2008; ERBIL, 2011). O uso de apenas uma defasagem do gasto governamental na modelagem empírica é suficiente para captar a inércia dos gastos governamentais na política fiscal brasileira. Diversos estudos têm apontado que o aumento das despesas obrigatórias, das transferências constitucionais e legais, da obrigação de aplicação mínima de recursos em áreas como saúde e educação, assim como a criação de uma série de receitas vinculadas a determinados gastos contribuem para um aumento da rigidez orçamentária, resultando em um engessamento da política fiscal. Além disso, a rigidez orçamentária pode estar associada a problemas de defasagem na condu-

1 Formalmente, o surgimento do hiato do produto na equação (3) pode ser derivado admitindo-se que, em estado estacionário, a razão $G_{t} / Y_{t}$ é constante. Outros estudos, como Alesina, Campante e Tabellini (2008), também usam o hiato do produto para analisar a ciclicidade da política fiscal. 
ção das políticas de estabilização macroeconômica, em razão de haver um hiato interno (defasagem de tempo) entre o reconhecimento do choque econômico e a implementação de ações em resposta a esse choque, tornando-se um problema fundamental inerente ao uso de políticas fiscais para fins de estabilização. Por exemplo, as decisões sobre gastos e tributação devem ter a participação do Congresso Nacional e o Poder Executivo Federal por meio de seus órgãos competentes, o que pode tornar o processo mais demorado.

O hiato do produto, $y_{t}^{c}$ capta a influência do nível de atividade econômica sobre a trajetória do gasto governamental. Definido como sendo a diferença entre o produto efetivo e o produto potencial de uma economia, o hiato do produto funciona como indicador de flutuações econômicas, proporcionando aos formuladores de política econômica a possibilidade de antecipar potenciais pressões de demanda sobre os preços, por exemplo. Valores positivos do hiato do produto indicam que o produto efetivo é superior ao potencial e sugerem a possibilidade de elevação futura do nível de preços, e vice-versa. O seu efeito sobre $g_{t}$ depende do coeficiente $\phi$, podendo ser pró-cíclico, acíclico ou contra-cíclico.

Com a finalidade de captar os efeitos da crise financeira internacional de 2008-2009 sobre o desempenho da economia brasileira, constrói-se uma variável dummy de nível (dcrise $e_{t}$ ), a qual é acrescentada na modelagem empírica, assumindo valor 1 entre os meses de outubro de 2008 a julho de 2009 , e zero no restante do período, haja vista que a recessão econômica afetou o comportamento de vários indicadores macroeconômicos e fiscais no período indicado, e resultou na adoção de medidas fiscais como resposta a essa crise. Por exemplo, no lado das receitas, as autoridades governamentais reduziram as alíquotas do imposto sobre produto industrializado (IPI), sendo a redução no IPI Automóveis a mais significativa, resultando em uma forte recuperação das vendas nesse setor. No lado das despesas, as medidas incluíram a extensão dos benefícios do seguro-desemprego, a manutenção e a expansão dos gastos em programas de transferência de renda (por exemplo, programa Bolsa Família), o aumento do salário mínimo e a implantação do programa habitacional "Minha Casa, Minha Vida" destinado às famílias de rendimentos médios e baixos para estimular o setor da construção civil. Além disso, o governo federal aumentou o seu próprio investimento (Programa de Aceleração do Crescimento - PAC) e expandiu o volume de crédito 
disponível ao setor privado por meio de instituições financeiras federais. Observou-se, também, uma redução da meta de superávit primário em proporção do $\mathrm{PIB}$, com a finalidade de não comprometer os planos de investimento público. Além disso, houve uma ampliação das transferências para estados e municípios com aportes financeiros feitos via bancos públicos. Caso seja constatada a natureza pró-cíclica da política fiscal, inclui-se o termo $\kappa\left(\right.$ fteo $\left._{t}\right)$ nas equações (4) e (5), em que $f$ teo $t_{t}=\left[\tau_{t},(\text { corrup })_{t},(P M P P / D V B C)_{t},(\text { autônomo })_{t}, f d i_{t}\right]$ é um vetor de variáveis associado a cada uma das teorias sobre próciclicidade da política fiscal a serem testadas. O vetor $\kappa$, dado por $\kappa=\left[\kappa^{\tau}, \kappa^{c}, \kappa^{i}, \kappa^{\alpha}, \kappa^{f}\right]$, representa a elasticidade do gasto governamental em relação a cada uma das teorias sobre pró-ciclicidade da política fiscal. Já o vetor $z_{t}$ representa um conjunto de variáveis de controle.

A hipótese da variabilidade da base tributária, defendida por Talvi e Vegh (2005), será testada pela variável receita governamental sobre o PIB $\left(\tau_{t}\right)$. Se a elasticidade do gasto governamental em relação à receita governamental for positiva $\left(\kappa^{\tau}>0\right)$ e estatisticamente significante, a teoria sobre a variabilidade da base tributária estaria validada para o caso brasileiro. Embora a tributação seja um dos pilares da política fiscal, o seu uso para definir a natureza cíclica da política fiscal possui algumas limitações. Kaminsky, Reinhart e Vegh (2004), por exemplo, argumentam que as receitas tributárias constituem um resultado de política que respondem endogenamente ao ciclo de negócios.

Mas, Vegh e Vuletin (2012) destacam que as receitas tributárias quase sempre aumentam durante as expansões econômicas e se reduzem nas recessões, à medida que a base tributária, baseada em impostos sobre a renda ou consumo, move-se positivamente com o ciclo de negócios. Nesse sentido, somente quando as receitas tributárias são negativamente relacionadas com o ciclo de negócios pode-se concluir que a política de alíquotas tributárias é pró-cíclica (VEGH e VULETIN, 2012).

Dada a ausência de uma série temporal de alíquotas tributárias para a economia brasileira, utilizou-se como proxy a razão de receita governamental sobre o PIB para testar a hipótese da variabilidade da base tributária. 
A fim de testar a teoria sobre corrupção proposta por Alesina, Campante e Tabellini (2008), como não há um índice de corrupção na frequência mensal para o caso brasileiro, utilizou-se como pro$x y$ a relação dos rendimentos médios reais efetivos dos empregados dos setores público e privado (corrupt). Se a elasticidade do gasto governamental em relação à corrupção for positiva $\left(\kappa^{c}>0\right)$ e estatisticamente significante, então a teoria da corrupção é validada para explicar a ciclicidade da política fiscal brasileira.

Mauro (1998) e Van Rijckeghem e Weder (1997) demonstram que a variável que melhor explicava a corrupção em baixos escalões do governo era a relação de salários entre o setor público e privado e, seguindo essa premissa, Lima (2004) utilizou essa variável como proxy de corrupção nos estados brasileiros. Assume-se que a baixa relação de salários entre os setores público e privado pode indicar a existência de corrupção, uma vez que os funcionários públicos, ao receberem salários muito baixos em comparação com atividades similares desempenhadas na iniciativa privada, podem ter incentivos a cobrarem propinas pelas suas atividades. Por sua vez, Maciel (2005) destaca que os salários dos servidores públicos são importantes na determinação da corrupção, na medida em que representam um custo para aqueles que forem descobertos. O salário representa a quantia que o indivíduo deverá abdicar caso seja descoberto e punido. Assim, um indivíduo que recebe um alto salário estaria menos disposto a colocar seu emprego em risco.

Esse indicador de corrupção, porém, não está imune a críticas. Por exemplo, Di Tella e Schargrodsky (2003) apud Maciel (2005) afirmam que a hipótese de altos salários pagos pelo setor público associada a baixos níveis de corrupção falha em algumas situações. A probabilidade de punição, que é influenciada pela intensidade das atividades de controle de auditoria no setor público, altera o comportamento dos funcionários públicos em relação ao nível dos salários. Se os funcionários públicos acreditam ser pouco provável que seus atos corruptos sejam descobertos, eles serão corruptos, apesar dos altos salários recebidos.

A economia informal, por sua vez, é composta por um conjunto de atividades que escapam do controle do Estado para reduzir seus custos e, com isso, elevar seus lucros. Estas atividades legais não declaradas ao governo buscam evadir impostos, contribuições à previdência 
social, leis e regulamentações trabalhistas e evitar gastos decorrentes do cumprimento de normas aplicáveis à determinada atividade. A fim de testar a hipótese da economia informal sugerida por Çicek e Elgin (2011), utilizaram-se as seguintes variáveis explicativas: trabalhadores autônomos (autônomo $)_{t}$ e relação $(P M P P / D V B C)_{t}$.

Segundo o IBGE, os trabalhadores autônomos são definidos como sendo a população ocupada que trabalha por conta própria, sem vínculo empregatício com nenhum estabelecimento. É importante destacar que empreendimentos informais surgem também a partir da decisão de trabalhadores de se tornarem autônomos, com o intuito de evitar não somente os elevados custos com a legislação trabalhista, mas também a cobrança oficial de impostos e contribuições (TIRYAKI, 2008).

No tocante à variável $(P M P P / D V B C)_{t}$, intuitivamente, quanto maior a proporção de moeda em poder do público, em relação à quantidade de depósitos, maior deve ser o tamanho da economia informal, haja vista que a existência de depósitos facilita a identificação de firmas que não cumprem as leis. Em outras palavras, atividades que fogem do controle tributário do Estado tendem a trabalhar mais com papel-moeda do que com depósitos à vista nos bancos comerciais ${ }^{2}$. TIRYAKI (2008) destaca que a economia informal se faz sentir "(...) na quantidade de transações monetárias, já que a remuneração e os dispêndios das atividades informais ocorrem normalmente em forma de papel-moeda (...)".

No tocante à teoria sobre economia informal, o vetor tteo $_{t}$ torna-se bidimensional, dado por $(P M P P / D V B C)_{t}$ e autônomo, com correspondente vetor de parâmetros dado por $\left[\kappa^{i}, \kappa^{\alpha}\right]$. Se esse vetor de parâmetros $\left[\kappa^{i}, \kappa^{\alpha}\right]$, que mede a sensibilidade do gasto governamental à economia informal, for positivo e estatisticamente significante, então é válida a teoria de que o tamanho da economia informal contribui para a pró-ciclicidade da política fiscal no Brasil (ÇICEK e ELGIN, 2011).

2 No período 2007-2009, a variável (PMPP/DVBC) $t$ compôs o índice da economia subterrânea elaborado pelo Instituto Brasileiro de Ética Concorrencial, conforme pode ser verificado nas apresentações metodológicas desse índice constantes no sítio eletrônico desse instituto (http://www.etco.org.br). Não obstante, a trajetória desse índice ao longo do período analisado deve ter sido influenciada pelas flutuações do nível de atividade econômica. 
Gavin e Perotti (1997a) comparam as principais características da política fiscal na América Latina com o comportamento da política fiscal nos países da OCDE, e observam que a política fiscal na América Latina é volátil e pró-cíclica. Posteriormente, ao examinarem a pró-ciclicidade do ingresso de fluxos de capitais e da política fiscal em uma amostra de 104 países abrangendo o período 1960-2003, Kaminsky, Reinhart e Vegh (2004) obtiveram resultados consistentes com as evidências obtidas por Gavin e Perotti (1997a), no sentido de que muitos países, especialmente os países em desenvolvimento, exibem uma política fiscal pró-cíclica, ao passo que as políticas fiscais tendem a ser anticíclicas ou acíclicas nas nações industrializadas. Em relação à teoria sobre a restrição ao crédito internacional defendida por Gavin e Perotti (1997a,b), a variável a ser testada será os ingressos de investimentos diretos estrangeiros $\left(f d i_{t}\right)$. Nesse sentido, essa teoria será validada se a elasticidade do gasto governamental em relação ao ingresso de investimentos diretos estrangeiros no país for positiva $\left(\kappa^{f}>0\right)$ e estatisticamente significante.

Utilizando uma amostra de 23 economias emergentes e 22 economias da OCDE no período 1971-2006, Strawczynski e Zeira (2011) constataram que, em nações com altos níveis de investimentos diretos estrangeiros, a pró-ciclicidade da política fiscal é mais suave. A necessidade de se cortar gastos em tempos ruins tem sido reduzida em países mais expostos a investidores internacionais.

Os modelos, dinâmico e estático, serão estimados usando-se o método GMM por causa da potencial endogeneidade de variáveis explicativas. Algumas variáveis de controle, como a taxa de desemprego (desempt) e uma dummy para a crise financeira mundial de 2008, serão inseridas nos modelos estimados para evitar erros de especificação. O estimador GMM permite que modelos econômicos sejam diretamente parametrizados, evitando suposições desnecessárias sobre a distribuição dos erros (HANSEN, 1982; HAMILTON, 1994, p. 409-415). Defina $r$ como sendo o número de condições de ortogonalidade (ou condições de momento) e $a$ como sendo o número de parâmetros. Seja $w_{t}$ um vetor $(h \times 1)$ de variáveis aleatórias do modelo observadas na data $t$; $\theta$ é um vetor $(a \times 1)$ de parâmetros desconhecidos a serem estimados; e $h\left(\theta, w_{t}\right)$ é uma função vetor valorada $(r \times 1), h\left(\mathbb{R}^{a} \times \mathbb{R}^{h}\right) \rightarrow \mathbb{R}^{r}$. Se $w_{t}$ é uma variável aleatória, $h\left(\theta, w_{t}\right)$ também o será. 
Seja $\theta_{0}$ o valor verdadeiro de $\theta$, caracterizado pela propriedade de que $E\left[h\left(\theta_{0}, w_{t}\right)\right]=0$. Seja $y_{t} \equiv\left(w^{\prime} T_{T}, w^{\prime} T_{-1}, \ldots, w_{1}^{\prime}\right)^{\prime}$ um vetor $(T h \times 1)$ contendo todas as observações na amostra de tamanho $T$.

Deve-se escolher $\theta$ de tal modo que o momento amostral $g\left(\theta ; \mathcal{Y}_{t}\right)$ esteja tão perto quando possível para o momento populacional de zero. O estimador GMM $\hat{\theta}_{\mathrm{T}}$ é o valor de $\theta$ que minimiza a seguinte função objetivo:

$$
\hat{\theta}^{G M M}=\frac{\arg \min Q\left(\theta ; \mathcal{Y}_{t}\right)}{\theta}=\left[g\left(\theta ; \mathcal{Y}_{t}\right)\right]^{\prime} W_{T}\left[g\left(\theta ; \mathcal{Y}_{t}\right)\right]
$$

em que a função $g\left(\theta ; \mathcal{Y}_{t}\right) \equiv \sum_{t=1}^{T} h\left(\theta, w_{t}\right) / T$ é o vetor $(r \times 1)$ de condições de ortogonalidade que representa a média amostral de $h\left(\theta_{0}, w_{t}\right)$ e deve ser comparado a $E\left[h\left(\theta_{0}, w_{t}\right)\right], g: \mathbb{R}^{a} \rightarrow \mathbb{R}^{r}$. O termo $\left\{W_{T}\right\}_{T=1}^{\infty}$ é uma seqüência de matrizes ponderadas simétricas definidas positivas $(r \times r)$ que podem ser uma função dos dados. Pode-se assumir que os $r$ instrumentos são pré-determinados, no sentido de que esses instrumentos são ortogonais ao termo de erro corrente.

A fim de operacionalizar o estimador GMM, o número de momentos $(r)$, deve ser maior do que o número de parâmetros $(a)$. Hansen (1982) desenvolveu um teste para identificar se um determinado momento adicional contribui para a estimação do vetor de parâme$\operatorname{tros} \theta$. A hipótese nula do teste de Hansen-Sargan, $H_{0}: h\left(\theta, w_{t}\right)=0$, baseia-se na pressuposição de que as condições de sobre-identificação (ou condições de momento) são válidas. Nesse sentido, a inclusão de mais de um momento não implica em rejeição da hipótese nula, de modo que esse momento adicional é ortogonal aos resíduos da regressão. Todavia, a estimação GMM requer estacionariedade das séries de tempo, o que será discutido na próxima seção.

\subsection{Testes de Raiz Unitária}

Os testes modificados de Dickey-Fuller e de Phillips-Perron $\left(\overline{M Z}_{\alpha}^{G L S}\right)$ , propostos por Elliot, Rottemberg e Stock (1996) e Ng e Perron (2001) são aplicados com a finalidade de verificar a estacionariedade das séries de tempo. Esses testes superam os problemas de baixo poder estatístico e distorções de tamanho dos testes tradicionais de 
Dickey e Fuller (1979, 1981), Said e Dickey (1984) e de Phillips e Perron (1988). As modificações no teste padrão de raiz unitária de Dickey e Fuller (1979, 1981) e de Said e Dickey (1984) fundamentam-se em dois aspectos centrais: a extração de tendência em séries de tempo usando mínimos quadrados ordinários (OLS) é ineficiente e a importância de uma seleção apropriada para a ordem de defasagem do termo aumentado, de modo a obter uma melhor aproximação para o verdadeiro processo gerador de dados.

No primeiro caso, Elliot, Rottemberg e Stock (1996) propõem usar mínimos quadrados generalizados (GLS) a fim de extrair a tendência estocástica da série. Emprega-se o procedimento padrão para estimar a estatística $A D F^{G L S}$ como sendo a estatística $t$ para testar a hipótese nula de presença de raiz unitária contra a hipótese alternativa de que a série é estacionária. Com relação ao segundo aspecto, $\mathrm{Ng}$ e Perron (2001) demonstram que os critérios de informação de Akaike (AIC) e de Schwarz (SIC) tendem a selecionar baixos valores para a defasagem, quando se tem uma grande raiz negativa (próximo a -1) no polinômio de médias móveis da série. Isso gera distorções e motivou o desenvolvimento do critério modificado de informação de Akaike (MAIC) para a seleção da defasagem autorregressiva, de modo a minimizar as distorções provocadas por seleção inadequada de defasagens.

Ng e Perron (2001) propõem que as mesmas modificações sejam aplicadas também ao teste tradicional de Phillips e Perron (1988), originando o teste $\left(\overline{M Z}_{\alpha}^{G L S}\right)$. Por meio de simulações, $\mathrm{Ng}$ e Perron (2001) mostram que a aplicação conjunta de GLS para extrair a tendência determinista e do critério de seleção de defasagens MAIC produzem testes com maior poder, mas menores distorções de tamanho estatístico quando comparados aos testes tradicionais ADF e PP. Os valores críticos das estatísticas $A D F^{G L S}$ e $\left(\overline{M Z}_{\alpha}^{G L S}\right)$ estão reportados em Ng e Perron (2001).

Contudo, mesmo os testes modificados $A D F^{G L S}$ e $\left(\overline{M Z}_{\alpha}^{G L S}\right)$ possuem baixo poder na presença de quebras estruturais, tornando-se enviesados no sentido da não rejeição da hipótese nula de raiz unitária, mesmo quando a série é estacionária. O trabalho pioneiro de Perron (1989) ilustra a importância de se incluir uma quebra estrutural nos testes tradicionais de raízes unitárias. Foram considerados três modelos de quebra estrutural. O Modelo A, que é conhecido como 
modelo crash, permite a mudança de um período no nível. O Modelo $B$, que permite a existência de uma quebra na tendência da série de tempo. O Modelo C, que é conhecido como changing growth path, inclui mudança de um período em ambos nível e tendência.

Pesquisas posteriores adotaram um procedimento endógeno para determinar o ponto de quebra a partir dos dados. Nesse contexto, Saikkonen e Lütkepohl (2002) e Lanne, Lütkepohl e Saikkonen $(2002,2003)$ propõem que as quebras estruturais podem ocorrer ao longo de um número de períodos e expõe uma transição suave para um novo nível. Portanto, uma função de mudança de nível é acrescentada ao termo determinístico do processo gerador de dados. Os termos determinísticos são extraídos por mínimos quadrados generalizados (GLS) e, em seguida, aplica-se um teste ADF às séries ajustadas. Valores críticos do teste encontram-se tabulados por Lanne, Lütkepohl e Saikkonen (2002).

\section{Descrição dos Dados}

Os dados consistem de observações mensais para o período de março de 2002 a julho de 2011. Com exceção do Produto Interno Bruto (PIB), cuja origem foi o Banco Central do Brasil, as demais variáveis foram obtidas no Instituto de Pesquisa Econômica Aplicada e na Secretaria do Tesouro Nacional. A justificativa para se trabalhar com o período em análise baseia-se em dois pontos. Primeiro, aspectos metodológicos e processuais da Pesquisa Mensal de Emprego (PME), sob responsabilidade do Instituto Brasileiro de Geografia e Estatística (IBGE), passaram por uma revisão completa, vigente desde março de 2002, haja vista as transformações ocorridas no mercado de trabalho brasileiro. E essa revisão atingiu as variáveis taxa de desemprego e trabalhadores autônomos. Segundo, não existem informações, anteriores a 2002, referentes aos rendimentos médios reais efetivos dos empregados dos setores público e privado, os quais serão utilizados na construção do indicador de corrupção.

As séries de receita líquida total e despesa total, em valores correntes ( $\mathrm{R} \$$ milhões), foram obtidas no sítio eletrônico da Secretaria do Tesouro Nacional (STN), e correspondem ao critério acima da linha, em que são explicitados os principais fluxos de receitas e despesas. 
A receita líquida total corresponde ao somatório das receitas do Tesouro, receitas da Previdência e receitas do Banco Central, excluídas as transferências a estados e municípios. Por sua vez, a despesa total corresponde ao somatório das despesas de pessoal e encargos sociais, benefícios previdenciários, custeio e capital, transferências do Tesouro ao Banco Central e despesas do Banco Central.

No tocante a essas séries fiscais, houve uma preocupação a priori de se excluir parcelas de receitas e despesas não explicadas pelo comportamento cíclico do PIB. Em setembro de 2010, as receitas e despesas do Tesouro Nacional foram impactadas pelas operações realizadas para a capitalização da Petrobrás, conforme informações constantes no Relatório do Tesouro Nacional para esse período. Especificamente, do lado dos dispêndios (rubrica Outras Despesas de Custeio e de Capital), $\mathrm{R} \$ 42,9$ bilhóes reflete a despesa com a operação de capitalização da Petrobras. Por outro lado, as demais receitas do Tesouro Nacional foram influenciadas pelo ingresso, em setembro, de $\mathrm{R} \$ 74,8$ bilhões a título de cessão onerosa para exploração de petróleo pela Petrobrás, conforme estabelecido na Lei ${ }^{\circ}$ 12.276, de 30 de junho de 2010. Haja vista que as operações realizadas para capitalização da Petrobrás se tratam de eventos que fogem à normalidade econômica, os valores descritos nessas operações também foram excluídos das séries de receita total líquida e de despesa total analisadas nesse estudo, por se tratarem de outliers.

As séries médias de papel-moeda em poder do público (PMPP) e de depósitos à vista nos bancos comerciais (DVBC), em valores correntes ( $\mathrm{R} \$$ milhões), obtidas no Ipeadata, porém tendo como fonte primária o Banco Central do Brasil. Referem-se à parcela dos meios de pagamentos, segundo o conceito $\mathrm{M}_{1}$, em outras palavras, correspondente ao agregado monetário de maior liquidez.

A série de investimentos diretos estrangeiros no país, ingressos em valores correntes e em dólares (US\$ milhões), igualmente obtida no Ipeadata, mas tendo como fonte primária o Banco Central do Brasil, foi convertida para o Real utilizando a taxa de câmbio nominal média (R\$/US\$), comercial para compra ${ }^{3}$.

\footnotetext{
${ }^{3}$ A conta financeira do balanço de pagamentos brasileiro registra os fluxos de capital entre residentes e não residentes e está organizada em quatro subcontas: investimento direto, investimento em carteira, derivativos e outros investimentos. Neste estudo, optou-se por não utilizar o saldo da conta financeira, em tese a medida mais ampla, porque envolve a participação de capital especulativo (investimento em carteira).
} 
As variáveis taxa de desemprego e trabalhadores por conta própria, contagem por mil pessoas, são apurados pelo IBGE em seis regiões metropolitanas do país (Recife, Salvador, Belo Horizonte, Rio de Janeiro, São Paulo e Porto Alegre). Os rendimentos médios reais efetivos dos empregados dos setores público e privado, em valores correntes (R\$), também são apurados pelo IBGE.

O tratamento dos dados ocorreu obedecendo as seguintes etapas. Em primeiro lugar, todas as séries em valores correntes foram convertidas em termos reais, deflacionadas pelo Índice Geral de Preços - Disponibilidade Interna (IGP-DI). Em seguida, as variáveis gasto governamental, receita governamental e ingresso de investimentos diretos estrangeiros são expressas em proporção do PIB. Essas novas séries em termos reais, juntamente com a série da variável trabalhadores autônomos, são tomadas na forma logarítmica, de modo que, os coeficientes estimados podem ser interpretados como elasticidades. $\mathrm{Na}$ terceira etapa, todas essas séries expressas em termos reais e na forma logarítmica são ajustadas sazonalmente pelo método Census $\mathrm{X}-12$.

Utiliza-se como proxy para o hiato do produto o componente cíclico da série mensal do PIB real, obtido usando o filtro Hodrick-Prescott - HP (1997), calculado como sendo a diferença entre o produto efetivo e o produto tendencial $\left(y_{t}^{c}=y_{t}-y_{t}^{T}\right)$. O filtro HP se constitui em um método de suavização utilizado para se obter uma estimativa dos componentes cíclicos e da tendência de longo prazo de uma série temporal. Apresenta algumas vantagens que têm levado a sua vasta utilização em comparação a outros filtros existentes como, por exemplo, o fato de garantir a estacionariedade do hiato do produto, conforme demonstrado por King e Rebelo (1993), além de ser considerado de simples implementação.

No Brasil, Ellery, Gomes e Sachsida (2002) analisaram as propriedades cíclicas de variáveis macroeconômicas utilizando o filtro Hodrick-Prescott (1997), e notaram que os resultados não são muito diferentes quando se emprega a aproximação do filtro band pass ideal proposta por Baxter e King (1995). Note que, apesar das várias limitações levantadas na literatura, o Banco Central do Brasil tem utilizado o filtro HP na série de produto industrial para a obtenção de uma medida do hiato do produto em seu modelo de metas inflacionárias, conforme citado no relatório Dez Anos de Metas para a 
Inflação (1999-2009) e no Relatório de Inflação para o mês de março de 2011, ambos publicados pelo Banco Central do Brasil, assim como em Bogdanski et al. (2001) ${ }^{4}$.

\section{Resultados}

\subsection{Testes de Raiz Unitária}

A Tabela 1 reporta os resultados dos testes de raízes unitárias aplicados às séries em nível. Os resultados dos testes $A D F^{G L S}$ e $\left(\overline{M Z}_{\alpha}^{G L S}\right)$ mostraram que apenas as variáveis desemp $t_{t}$ e $(P M P P / D V B C)_{t}$ apresentaram estacionariedade em nível em modelos com constante e tendência determinística, aos níveis de significância de 5\% e 10\%, respectivamente, em outras palavras, tratam-se de séries $\mathrm{I}(0)$.

Como as demais séries analisadas não se apresentaram estacionárias em nível, e haja vista as mudanças na condução da política econômica no período analisado, houve a necessidade de se ampliar a investigação da estacionariedade das séries por meio da aplicação de testes de raiz unitária com quebra estrutural.

Inicialmente, aplicou-se o teste de Perron (1989), selecionando-se exogenamente como data da quebra estrutural os meses de outubro de 2008 a julho de 2011, ou seja, período em que os efeitos da crise financeira internacional afetaram o desempenho da economia brasileira e exigiram uma reação do governo federal por meio de políticas de estabilização macroeconômica anticíclicas. À exceção da série de trabalhadores autônomos, todas as demais séries se mantiveram estacionárias em nível, aos níveis de significância estatística de 1\%, 5\% e $10 \%$.

${ }^{4}$ Custinato, Minella e Pôrto Júnior (2010) utilizaram três métodos de extração de tendência com a finalidade de analisar as revisões do hiato da produção industrial, a saber, o filtro de Hodrick-Prescott (HP), a tendência linear (TL) e a tendência quadrática (TQ), no período de abril de 1998 a outubro de 2008. Dentre os resultados obtidos, observou-se que os hiatos da produção industrial obtidos pelos métodos HP, TL e TQ são revisados, em média, respectivamente, 1,26 p.p., 2,02 p.p. e 3,18 p.p. acima ou abaixo das suas estimativas iniciais. Além disso, os métodos TL e TQ apresentaram tanto as maiores magnitudes de revisão, quanto os maiores vieses. Notou-se que, em dois dos três métodos (HP e TQ), as revisões implicam mudança de sinal do hiato em $30 \%$ ou mais das vezes, e a magnitude da revisão é maior do que a própria magnitude do hiato em aproximadamente $50 \%$ ou mais das vezes. 
Em seguida, aplicou-se o teste de Saikkonen e Lütkepohl (2002), cujos resultados apontam para a estacionariedade em nível de todas as séries analisadas neste estudo. No tocante à taxa de desemprego, $\left(\right.$ desemp $\left._{t}\right)$ a data selecionada de quebra estrutural está associada ao período da crise financeira internacional. No tocante às variáveis trabalhadores autônomos (autonomot) e indicador de corrupção $\left(\right.$ corrup $\left._{t}\right)$, os meses de setembro e outubro de 2002 estão associados à crise de confiança externa sobre a evolução da economia brasileira no período pré-eleitoral.

Em relação à série de receita governamental/PIB $\left(\tau_{t}\right)$, a data da quebra de fevereiro de 2003 pode estar associada a fatores como o pagamento da $1^{\text {a }}$ cota ou cota única do Imposto de Renda Pessoa Jurídica (IRPJ) e da Contribuição Social sobre o Lucro Líquido (CSLL), em janeiro de 2003, relativa ao resultado apurado no último trimestre de 2002. Essa informação consta no relatório Análise da Arrecadação das Receitas Federais, elaborado pela Secretaria da Receita Federal, bem como no Resultado do Tesouro Nacional, ambos para o mês de fevereiro de 2003.

Quanto ao ingresso de investimentos diretos estrangeiros ( $\left.f d i_{t}\right)$, no mês de agosto, isto é, um mês posterior à quebra estrutural selecionada endogenamente, registrou-se a fusão entre a empresa belga Interbrew e a Companhia de Bebidas das Américas (Ambev), representando investimento estrangeiro de US $\$ 4,9$ bilhões, realizado pela Interbrew, e investimento brasileiro no exterior, de igual montante, feito pela Ambev. Apesar dessa operação não ter requerido movimentação de divisas, gerou consequências econômicas, além de impactar os estoques de investimentos estrangeiros no país e de brasileiros no exterior, conforme destaca o Relatório Anual 2004 do Banco Central.

Sobre o indicador de economia informal $(P M P P / D V B C)_{t}$, o Relatório de Inflação de dezembro de 2004, elaborado pelo Banco Central do Brasil, evidencia a retomada da trajetória de alta do agregado monetário $\mathrm{M}_{1}$, traduzido em expansões no saldo médio do papel-moeda em poder do público e nos depósitos à vista, em função do crescimento contínuo da atividade econômica e da evolução do volume das operações de crédito, segundo Relatório de Inflação para o mês de dezembro de 2004. 
Tabela 1 - Testes de Raiz Unitária com e sem Quebra Estrutural

\begin{tabular}{|c|c|c|c|c|c|c|c|c|c|c|}
\hline \multirow{3}{*}{ Variáveis } & \multirow{3}{*}{ Modelo } & \multicolumn{3}{|c|}{ Sem Quebra Estrutural } & \multicolumn{6}{|c|}{ Com Quebra Estrutural } \\
\hline & & \multirow[t]{2}{*}{$A D F^{G L S}$} & \multirow[t]{2}{*}{$\overline{M Z}_{\alpha}^{G L S}$} & \multirow[t]{2}{*}{ Lags } & \multicolumn{4}{|c|}{$\begin{array}{l}\text { Saikkonen-Lütkepohl (2002) } \\
\text { Data da quebra é desconhecida }\end{array}$} & \multicolumn{2}{|c|}{$\begin{array}{c}\text { Perron (1989) } \\
\text { Data da quebra é } \\
\text { conhecida }\end{array}$} \\
\hline & & & & & $\begin{array}{l}\text { Tipo de } \\
\text { Quebra }\end{array}$ & $\begin{array}{l}\text { Data da } \\
\text { Quebra }\end{array}$ & $\begin{array}{c}\text { Estatística } \\
\text { de teste }\end{array}$ & Lags & $\begin{array}{l}\text { Tipo de } \\
\text { Modelo } \\
\end{array}$ & $\begin{array}{c}\text { Estatística } \\
\text { de teste }\end{array}$ \\
\hline$g_{t}$ & C & $-0,30$ & $-0,06$ & 11 & \multirow{2}{*}{$\begin{array}{l}\text { Impulse } \\
\text { Dummy }\end{array}$} & \multirow{2}{*}{ 2010:02 } & $-3,25^{\star *}$ & 1 & \multirow{2}{*}{ C } & \multirow{2}{*}{$-9,96^{\star \star \star}$} \\
\hline$g_{t}$ & $\mathrm{C}, \mathrm{T}$ & $-1,95$ & $-1,66$ & 11 & & & $-5,65^{\star \star \star}$ & - & & \\
\hline$\tau_{t}$ & $\mathrm{C}$ & 1,10 & 2,54 & 12 & \multirow{2}{*}{$\begin{array}{c}\text { Rational } \\
\text { Shift }\end{array}$} & \multirow{2}{*}{ 2003:02 } & $-4,46^{\star \star *}$ & 2 & \multirow{2}{*}{ A } & \multirow{2}{*}{$-9,24^{\star \star *}$} \\
\hline$\tau_{+}$ & $\mathrm{C}, \mathrm{T}$ & $-1,43$ & $-0,89$ & 12 & & & $-3,96^{\star \star \star}$ & - & & \\
\hline$y_{t}^{c}$ & C & $-1,19$ & $-1,13$ & 2 & \multirow{2}{*}{$\begin{array}{l}\text { Impulse } \\
\text { Dummy }\end{array}$} & \multirow{2}{*}{ 2009:12 } & $-3,56^{\star \star \star}$ & 2 & \multirow{2}{*}{ A } & \multirow{2}{*}{$-4,36^{\star \star}$} \\
\hline$y_{t}^{c}$ & $\mathrm{C}, \mathrm{T}$ & $-1,97$ & $-1,89$ & 2 & & & $-2,45$ & 3 & & \\
\hline$(P M P P / D V B C)_{t}$ & C & $-0,11$ & 0,02 & 5 & \multirow{2}{*}{$\begin{array}{c}\text { Rational } \\
\text { Shift }\end{array}$} & \multirow{2}{*}{ 2004:12 } & $-0,13$ & 5 & \multirow{2}{*}{ C } & \multirow{2}{*}{$-3,97^{\star}$} \\
\hline$(P M P P / D V B C)_{t}$ & $\mathrm{C}, \mathrm{T}$ & $-2,60$ & $-2,81^{*}$ & 5 & & & $-2,96^{*}$ & 5 & & \\
\hline autônomo ${ }_{t}$ & C & 0,28 & 0,32 & 1 & \multirow{2}{*}{$\begin{array}{c}\text { Rational } \\
\text { Shift }\end{array}$} & \multirow{2}{*}{ 2002:10 } & $-1,42$ & 1 & \multirow{2}{*}{ C } & \multirow{2}{*}{$-2,68$} \\
\hline autônomo $t$ & $\mathrm{C}, \mathrm{T}$ & $-1,06$ & $-0,99$ & 1 & & & $-3,46^{\star *}$ & 1 & & \\
\hline desemp $p_{t}$ & $C$ & 0,65 & 0,77 & 12 & \multirow{2}{*}{$\begin{array}{c}\text { Shift } \\
\text { Dummy }\end{array}$} & \multirow{2}{*}{ 2009:01 } & 1,01 & 9 & \multirow{2}{*}{ C } & \multirow{2}{*}{$-4,19^{\star \star}$} \\
\hline desemp $p_{t}$ & $\mathrm{C}, \mathrm{T}$ & $-3,48^{* *}$ & $-3,15^{\star \star}$ & - & & & $-3,57^{\star \star \star}$ & 2 & & \\
\hline$f d i_{t}$ & C & $-0,87$ & $-0,86$ & 7 & \multirow{2}{*}{$\begin{array}{l}\text { Impulse } \\
\text { Dummy }\end{array}$} & 2004.07 & $-5,42^{\star \star \star}$ & 2 & $B$ & $102 \bigwedge^{\star \star \star *}$ \\
\hline$f d i_{t}$ & $\mathrm{C}, \mathrm{T}$ & $-1,24$ & $-0,95$ & 8 & & 2004.01 & $-4,99^{\star \star \star}$ & 2 & $D$ & $-10,24$ \\
\hline corrup $_{t}$ & C & $-0,06$ & 0,26 & 4 & Rational & & $-1,23$ & 4 & $D$ & \\
\hline corrup $_{t}$ & $\mathrm{C}, \mathrm{T}$ & $-2,11$ & $-1,69$ & 4 & Shift & 2002.10 & $-3,87^{\star \star \star}$ & 2 & $D$ & $-0,01$ \\
\hline
\end{tabular}

Notas:

1- "Lags" significa defasagens. "C" significa constante. "T" significa tendência determinística. $\left({ }^{* * *}\right)$ significância a $1 \%$; $\left(^{* *}\right)$ significância a $5 \% ;\left(^{*}\right)$ significância a $10 \%$. Contagem inicial máxima de 12 defasagens.

2- Os valores críticos do teste $A D F^{G L S}$ são (Elliot, Rothenberg e Stock, 1996): (i) modelo com constante: $-2,58(1 \%)$; $-1,94(5 \%)$ e -1,61 (10\%). (ii) modelo com constante e tendência determinística: $-3,57$ (1\%); -3,03 (5\%) e -2,74 (10\%). Os valores críticos assintóticos do teste $\overline{M Z} \bar{Z}_{\alpha}^{G L S}$ são (Ng e Perron, 2001, Tabela 1): (i) modelo com constante: -2,58 (1\%); -1,98(5\%) e -1,62 (10\%). (ii) modelo com constante e tendência determinística: -3,42 (1\%); -2,91 (5\%) e - $2,62(10 \%)$.

3- Os valores críticos do teste de Saikkonen-Lütkepohl são os seguintes (Lanne et al. 2002): (i) modelo com constante: $-3,48$ (1\%); -2,88 (5\%) e -2,58 (10\%); (ii) modelo com constante e tendência determinística: $-3,55$ (1\%); -3,03 (5\%) e -2,76 (10\%).

4- Os valores críticos do teste de Perron (Perron, 1989, p. 1376-1377) são os seguintes considerando-se fração de quebra . (i) Modelo A: -4,42 (1\%); -3,80 (5\%); e -3,51 (10\%); (ii) Modelo B: -4,51 (1\%); -3,85 (5\%); e -3,57 (10\%); (iii) Modelo C: -4,75 (1\%); -4,18 (5\%); e $-3,86(10 \%)$.

No caso da variável hiato do produto $y_{t}^{c}$, a data de quebra em dezembro de 2009 está associada ao novo ciclo de estabilidade da economia brasileira, amparado pela adequação das medidas de política econômica implementadas ao final de 2008 e início de 2009 para o enfrentamento dos impactos da crise mundial, conforme destacado no Relatório de Inflação do Banco Central do Brasil para o mês de 
dezembro de 2009. O Relatório do Tesouro Nacional para o mês de fevereiro de 2010 destaca que as despesas do Tesouro Nacional apresentaram decréscimos nas despesas discricionárias e no pagamento de pessoal e encargos sociais. Esse fato deve ter influenciado a trajetória da variável gasto governamental/PIB $\left(g_{t}\right)$ analisada neste estudo.

Em resumo, os resultados dos testes de Saikkonen e Lütkepohl (2002) e de Perron (1989) indicam que as variáveis analisadas nesse estudo são estacionárias em nível, ou seja, tratam-se de variáveis I(0).

\subsection{Estimações Empíricas}

O problema da endogeneidade faz com que o uso de estimações OLS possa gerar estimadores inconsistentes, uma vez que a endogeneidade pode ocorrer por causa do hiato do produto, que é a medida utilizada nesse estudo como proxy para nível de atividade econômica, ou de outras variáveis presentes nas equações estáticas e dinâmicas a serem estimadas. Todavia, a abordagem GMM explora as condições de ortogonalidade entre o termo de erro e as variáveis instrumentais no conjunto de informações. No tocante aos modelos estáticos, a metodologia GMM será aplicada para estimar o vetor de parâmetros $\theta=(\alpha, \phi, \gamma, \kappa, \delta)^{\prime}$, ao passo que nos modelos dinâmicos estima-se o seguinte vetor de parâmetros $\tilde{\theta}=(\alpha, \beta, \phi, \gamma, \kappa, \delta)^{\prime}$. No modelo básico, em suas versões estática e dinâmica, as variáveis que testam as teorias sobre pró-ciclicidade da política fiscal não são incluídas nas estimações GMM, mas nos demais casos, o modelo muda de acordo com a teoria que está sendo testada a respeito da natureza pró-cíclica da política fiscal. As condições de momento (isto é, os instrumentos) serão representadas por constante, variáveis defasadas e variável dummy de crise mundial. Nesse sentido, observam-se as seguintes condições de ortogonalidade para os modelos estáticos e dinâmicos:

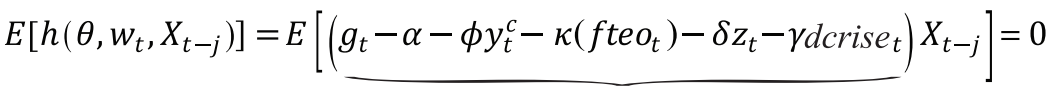

$$
\begin{aligned}
& =\varepsilon_{t}\left(\theta_{0}, w_{t}\right)
\end{aligned}
$$

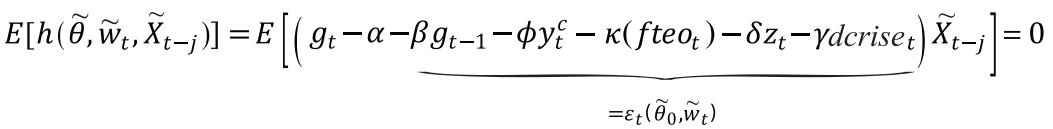


onde $w_{t}=\left(g_{t}, y_{t}^{c}, \tau_{t}, \text { corrup }_{t}, \text { autônomo } t,(P M P P / D V B C)_{t}, \text { fdi }_{t}, \text { desemp }_{t}, X_{t-j}\right)^{\prime}$ e $\widetilde{w}_{i}=g_{t}, g_{t-1}, y_{t}^{c}, \tau_{t}$, corrup $_{t}$, autônomo ${ }_{t},(P M P P / D V B C)_{t}$, fdi $_{t}$, desemp $\left._{t}, \widetilde{X}_{t-j}\right)^{\prime}$ são os vetores de variáveis observadas e usam as condições de ortogonalidade para a estimação. A condição de ortogonalidade resulta que qualquer vetor $(r \times 1)$ de variáveis instrumentais $X_{t-j}$ e $\tilde{X}_{t-j}$, os quais contêm valores defasados das variáveis e que representam um subconjunto da informação disponível na data $t$ $-j$, devem ser não correlacionados com o termo de erro. Dado $T$ observações nos vetores de variáveis $w_{t} \mathrm{e} \widetilde{w}_{t}$, os vetores de parâme$\operatorname{tros} \theta$ e $\tilde{\theta}$ e são estimados como sendo os vetores que minimizam a equivalente amostra de condições de ortogonalidade para uma matriz de pesos apropriada.

A Tabela 2 a seguir apresenta os resultados referentes aos modelos dinâmicos. Os resultados das estimações dos modelos estáticos serão reportados no apêndice desse artigo, os quais corroboram as evidências obtidas por meio das estimações dos modelos dinâmicos. O teste de Hansen-Sargan não rejeita a hipótese nula de que as condições de sobre-identificação são válidas.

Observe que, ao longo de todos os modelos dinâmicos estimados, a elasticidade do gasto governamental/PIB defasado $(\beta)$ é positiva e estatisticamente significante aos níveis de $1 \%$ e $5 \%$, evidenciando que as decisões de política fiscal são influenciadas pelo comportamento passado do gasto governamental, haja vista a presença de rigidez orçamentária. Essa rigidez pode ser resultado de diversos fatores, por exemplo, a existência de vinculação de receitas, a trajetória crescente das despesas obrigatórias (constitucionais e legais) e a defasagem temporal devido ao longo processo político observado na tomada de decisões para se alterar a trajetória de gastos e de impostos. Todavia, a magnitude desse coeficiente de rigidez orçamentária diminui à medida que se acrescenta as variáveis que testam as teorias sobre o comportamento pró-cíclico da política fiscal e outros controles.

No tocante ao modelo básico, a elasticidade dos gastos governamentais em relação ao hiato do produto é positiva $(\phi>0)$ e estatisticamente significante ao nível de 5\%, evidenciando o comportamento pró-cíclico da política fiscal brasileira no período analisado. Assim como será observado no caso dos modelos estáticos, a robustez desse parâmetro é mantida nas demais estimações GMM dinâmicas ao nível de significância de $1 \%$, o que motiva o acréscimo de variáveis 
explicativas ao modelo básico com o objetivo de analisar quais são as causas da pró-ciclicidade da política fiscal segundo as teorias a serem testadas.

Tabela 2 - Teorias sobre Política Fiscal Pró-Cíclica em Modelos Dinâmicos

\begin{tabular}{|c|c|c|c|c|c|}
\hline \multirow{2}{*}{$\begin{array}{l}\text { Variáveis } \\
\text { Explicativas }\end{array}$} & \multicolumn{5}{|c|}{ Variável Dependente: Gasto Governamental/PIB } \\
\hline & $\begin{array}{l}\text { Modelo } \\
\text { Básico }^{1}\end{array}$ & $\begin{array}{l}\text { Var. Base } \\
\text { Tributária }^{2}\end{array}$ & Corrupção $^{3}$ & $\begin{array}{l}\text { Economia } \\
\text { Informal }^{4}\end{array}$ & $\begin{array}{c}\text { Liquidez } \\
\text { Internacional }^{5}\end{array}$ \\
\hline Constante & $\begin{array}{c}0,7565^{\star \star \star} \\
(0,0002)\end{array}$ & $\begin{array}{c}0,1899^{\star \star \star} \\
(0,0000)\end{array}$ & $\begin{array}{c}0,3115^{\star \star \star} \\
(0,0000)\end{array}$ & $\begin{array}{l}-0,0418^{\star *} \\
(0,0339) \\
\end{array}$ & $\begin{array}{c}0,7109^{\star \star *} \\
(0,0000)\end{array}$ \\
\hline$g_{t-1}$ & $\begin{array}{l}0,3512^{\star *} \\
(0,0387)\end{array}$ & $\begin{array}{c}0,1242^{\star \star \star} \\
(0,0000)\end{array}$ & $\begin{array}{c}0,1241^{\star \star \star} \\
(0,0002)\end{array}$ & $\begin{array}{c}0,1893^{\star * \star} \\
(0,0000)\end{array}$ & $\begin{array}{c}0,4653^{\star \star \star} \\
(0,0000)\end{array}$ \\
\hline$y_{t}^{c}$ & $\begin{array}{l}0,2641^{* *} \\
(0,0538)\end{array}$ & $\begin{array}{c}0,0972^{\star \star \star} \\
(0,0002)\end{array}$ & $\begin{array}{c}0,1456^{\star \star \star} \\
(0,0000)\end{array}$ & $\begin{array}{c}0,0912^{\star \star \star} \\
(0,0000)\end{array}$ & $\begin{array}{c}0,0672^{\star \star \star} \\
(0,0001)\end{array}$ \\
\hline dcrise $_{t}$ & $\begin{array}{l}0,0211^{\star *} \\
(0,0238)\end{array}$ & $\begin{array}{c}0,0097^{\star \star \star} \\
(0,0000)\end{array}$ & $\begin{array}{c}0,0121^{\star \star \star} \\
(0,0000)\end{array}$ & $\begin{array}{c}0,0091^{\star \star \star} \\
(0,0000)\end{array}$ & $\begin{array}{c}0,0120^{\star \star \star} \\
(0,0000)\end{array}$ \\
\hline$\tau_{t}$ & - & $\begin{array}{c}0,2239^{* * \star} \\
(0,0000)\end{array}$ & - & - & - \\
\hline$(P M P P / D V B C)_{t}$ & - & $\begin{array}{c}0,8264^{\star \star \star} \\
(0,0000)\end{array}$ & - & $\begin{array}{c}0,6616^{\star * *} \\
(0,0000)\end{array}$ & \\
\hline corrup $_{t}$ & - & - & $\begin{array}{c}0,6511^{\star \star *} \\
(0,0000)\end{array}$ & - & - \\
\hline autônomo ${ }_{t}$ & - & - & - & $\begin{array}{c}0,0426^{\star \star \star} \\
(0,0000)\end{array}$ & - \\
\hline$f d i_{t}$ & - & - & - & - & $\begin{array}{c}-0,0845^{\star \star \star} \\
(0,0000)\end{array}$ \\
\hline Hansen-Sargan & $\begin{array}{c}4,4188 \\
(0,1098)\end{array}$ & $\begin{array}{c}1,7590 \\
(0,1847)\end{array}$ & $\begin{array}{c}1,9605 \\
(0,1614)\end{array}$ & $\begin{array}{c}2,0495 \\
(0,3588)\end{array}$ & $\begin{array}{c}0,8544 \\
(0,3552)\end{array}$ \\
\hline
\end{tabular}

Notas: ${ }^{* *}$ - significância a $1 \% ; * *$ - significância a $5 \%{ }^{*}$ - significância a $10 \%$. Os termos entre parênteses são os valores-p.

1 - Estimação da matriz de ponderação: HAC (lags $=1$, Bartlett Kernel, Bandwidth Newey-West fixado $=5,0000$ ). Instrumentos utilizados (6): constante, $g_{t-1}, y_{t-3}^{c}, y_{t-4}^{c}, y_{t-5}^{c}$ e dcrise $e_{t}$.

2- Estimação da matriz de ponderação: HAC (lags $=11$, Bartlett Kernel, Bandwidth Newey-West fixado $=5,0000)$. Instrumentos utilizados (7): constante, $g_{t-1}, y_{t-1}^{c}, \tau_{t}, \tau_{t-1},(P M P P / D V B C)_{t-2}$ e dcrise . $_{\text {. }}$

3- Estimação da matriz de ponderação: $\operatorname{HAC}\left(\operatorname{lag}_{s}=10\right.$, Bartlett Kernel, Bandwidth Newey-West fi-

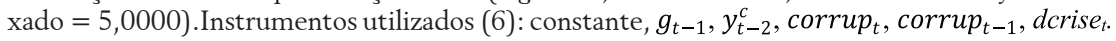

4- Estimação da matriz de ponderação: HAC (lags $=11$, Bartlett Kernel, Bandwidth Newey-West fixado $=5,0000)$. Instrumentos utilizados (8): constante, $g_{t-1}, y_{t-1}^{c}(P M P P / D V B C)_{t},(P M P P /$ DVBC $_{t-1}$, autônomo $_{t}$, autônomo $_{t-1}$, dcrise $_{t}$

5- Estimação da matriz de ponderação: $\operatorname{HAC}$ (lags $=13$, Bartlett Kernel, Bandwidth Newey-West fixado $=5,0000)$. Instrumentos utilizados (6): constante, $g_{t-1}, y_{t-1}^{c}, f d i_{t}, f d i_{t-1}$ e $d c r i s e_{t}$.

Por sua vez, a variável dummy para a crise mundial de 2008-2009 se mostra positiva e estatisticamente significante aos níveis de $1 \%$ e $5 \%$, demonstrando que essa crise exerceu um impacto no comportamento das variáveis fiscais sob análise. Além disso, esse resultado indica que houve um aumento do gasto governamental médio durante o período dessa crise econômica. 
No que diz respeito à teoria sobre variabilidade da base tributária, o parâmetro da receita governamental/PIB se mostra positivo e estatisticamente significante ao nível de $1 \%$, corroborando as evidências obtidas por Talvi e Vegh (2005), os quais argumentam que pressões políticas relacionadas aos gastos governamentais aumentam quando o superávit orçamentário se eleva em "tempos bons". Incapaz de resistir a essas pressões, o governo aumenta os gastos governamentais em períodos de expansão econômica. Como consequência, quanto maior a variabilidade da base tributária, mais pró-cíclica é a política fiscal. Dado que as nações em desenvolvimento fundamentam seus sistemas tributários em impostos sobre o consumo, as evidências obtidas por Talvi e Vegh (2005) sugerem que as bases tributárias desses países são três vezes mais voláteis do que em economias industrializadas. Argumenta-se que os governos desses países consideram difícil seguir políticas fiscais anticíclicas uma vez que a volatilidade dos fluxos de receita interage com as pressões políticas para gastar mais em "tempos bons".

No caso brasileiro, a variabilidade da base tributária pode estar associada a diversos fatores, por exemplo, as constantes mudanças nas alíquotas de tributos que compõem a arrecadação do governo federal. A receita líquida total utilizada nesse estudo corresponde ao somatório das receitas do Tesouro Nacional, da Previdência Social e do Banco Central, excluídas as transferências a Estados e Municípios. As receitas do Tesouro Nacional, em particular, são compostas pela arrecadação do imposto de renda, do imposto sobre produtos industrializados e de outros impostos, assim como pela arrecadação de contribuições como a COFINS, a CSLL, o PIS/Pasep e outras contribuições. Esses impostos e contribuições apresentaram frequentes mudanças em suas alíquotas durante o período analisado.

Giambiagi (2008) relata que, entre os anos 1991 e 2008, a receita do governo federal passou de $10,1 \%$ do PIB para $18,1 \%$, aproximadamente, tendo destaque: o aumento da receita do imposto de renda devido aos aperfeiçoamentos da máquina de arrecadação; a maior tributação associada ao recolhimento de imposto de renda na fonte sobre aplicações financeiras; o reforço da CSLL, uma espécie de imposto de renda sobre as pessoas jurídicas, porém não compartilhado, criado no início dos anos de 1990 e que responde por uma receita da ordem de 1,5\% do PIB; as sucessivas majorações da alíquota da 
COFINS que fizeram mais do que triplicar o peso deste tributo no PIB entre 1991 e 2008.

Thomas (2010, p. 17) destaca também que o alto grau de vinculação das receitas do orçamento do governo contribui para o comportamento pró-cíclico da política fiscal, uma vez que determinadas despesas, como gastos com saúde e educação, são atreladas constitucionalmente ao desempenho da arrecadação de impostos. Assim, em situações de crescimento econômico e aumento das receitas, o governo deve também aumentar o seu montante de recursos direcionados a determinados gastos.

Quanto à análise da influência da corrupção na natureza pró-cíclica da política fiscal, nota-se que a elasticidade do gasto governamental à corrupção mostra-se positiva e estatisticamente significante ao nível de $1 \%$ na estimação GMM. Alesina, Campante e Tabellini (2008) argumentam que a corrupção está associada à natureza pró-cíclica da política fiscal, segundo um modelo teórico no qual os constituintes não confiam em governos corruptos quando se trata de gerenciamento de recursos orçamentários adicionais. Em uma estrutura teórica de agente-principal, na qual os constituintes (eleitores) representam o principal e o governo representa o agente, em países onde há corrupção no processo político-orçamentário, os constituintes tendem a acreditar que qualquer receita governamental adicional será desviada através da distribuição de favores a grupos especiais junto ao governo, conhecidos como "caçadores de renda" (rent-seeking). Assim, os constituintes demandam aumentos nos gastos públicos, transferências ou investimentos públicos, sempre que a economia experimenta um choque positivo. Em resumo, quando os cidadãos se deparam com governos corruptos cujas escolhas de consumo e endividamento são difíceis de serem observadas, bem como acreditam que existem desvios de recursos orçamentários em períodos de expansão econômica, então eles irão demandar maiores gastos governamentais para conter esses governos corruptos. Essa demanda obriga os governos a adotarem uma política fiscal pró-cíclica.

Em relação à teoria da economia informal, os coeficientes das variáveis $(P M P P / D V B C)_{t}$ são positivos e estatisticamente significantes ao nível de $1 \%$, corroborando os argumentos defendidos por Çicek e Elgin (2011) de que a presença de uma maior economia informal afeta as propriedades cíclicas da política fiscal por meio do aumento 
da variabilidade da base tributária (TALVI e VEGH, 2005). A literatura econômica estabelece que a parcela da economia informal no total da atividade econômica exibe um padrão anticíclico, no sentido que o tamanho da economia informal expande durante as recessões e contrai durante as expansões econômicas (ROCA et al., 2003). Em nações industrializadas, caracterizadas por adotarem políticas fiscais anticíclicas segundo conceito adotado por Ilzetzki (2011) ${ }^{5}$, Çicek e Elgin (2011) argumentam que esse movimento da economia informal contribui para a expansão da base tributária durante as expansões econômicas (representando menor economia informal), assim como contração da base tributária durante as recessões (representando maior economia informal).

Mas, em países em desenvolvimento, caracterizados por adotarem políticas fiscais pró-cíclicas, ao amplificar as flutuações na base tributária, a presença de uma maior economia informal pode diminuir a anticiclicidade dos déficits orçamentários e dos gastos governamentais por meio do mecanismo sugerido por Talvi e Vegh (2005).

A economia informal está ligada à atividade de evasão fiscal, uma vez que empregadores e trabalhadores na economia informal não pagam impostos sobre seus rendimentos, nem os seus clientes pagam impostos relevantes sobre a mercadoria comprada. No caso brasileiro, essa situação afeta as decisões de política fiscal uma vez que o governo deverá elevar as alíquotas tributárias para o setor formal da economia a fim de compensar a perda de receita governamental do setor informal e, por outro lado, a existência de um elevado gasto governamental requer maior arrecadação tributária para financiá-lo.

Essa análise é confirmada a partir dos resultados do modelo dinâmico, em que o parâmetro do gasto governamental defasado se mostra positivo e estatisticamente significante ao nível de $1 \%$ na estimação GMM. Como a natureza pró-cíclica do gasto governamental responde, em grande parte, à capacidade de financiamento pelo Estado, então o crescimento da economia informal, ao aumentar a carga tributária do setor formal da economia, contribui também para o comportamento pró-cíclico da política fiscal no Brasil, em consonância com a análise realizada por Çicek e Elgin (2011) para países em desenvolvimento.

5 Conforme visto anteriormente, a política fiscal anticíclica refere-se à combinação de gastos anticíclicos, alíquotas tributárias pró-cíclicas ou acíclicas, e déficits orçamentários anticíclicos (ILZETZKI, 2011). 
Em relação à teoria sobre liquidez internacional, Gavin e Perotti (1997a,b) argumentam que os governos de países em desenvolvimento são incapazes de executarem políticas fiscais anticíclicas devido às rigorosas restrições ao crédito internacional que não os permitem obterem empréstimos durante períodos de desaceleração econômica. Quando há restrições aos empréstimos internacionais, esses governos não têm escolha a não ser confiar nas receitas governamentais para financiar os gastos, forçando-os a cortar gastos ou aumentar tributação nas recessões, resultando em política fiscal pró-cíclica. Entretanto, observe que a elasticidade do gasto governamental aos ingressos de investimentos diretos estrangeiros no país mostra-se negativa e estatisticamente significante ao nível de $1 \%$ na estimação GMM, sugerindo um fluxo anticíclico dos capitais internacionais, contradizendo dessa forma os argumentos defendidos por Gavin e Perotti (1997a,b) e Kaminsky, Reinhart e Vegh (2004). Esse resultado indica que uma maior entrada líquida de capitais contribui para reduzir o comportamento pró-cíclico da política fiscal no período analisado, corroborando as evidências empíricas obtidas por Erbil (2011) em nações produtoras de petróleo com médias e altas rendas no período 1991-2009.

\section{Considerações Finais}

Esse estudo teve como objetivo investigar o comportamento cíclico da política fiscal no Brasil, no período de março de 2002 a julho de 2011, testando as principais teorias que buscam explicar por que nos países em desenvolvimento as constatações teóricas e empíricas existentes apontam para a natureza pró-cíclica da política fiscal. A fim de atingir essa finalidade, utilizou-se a metodologia GMM na estimação de modelos estáticos e dinâmicos, sendo esses últimos importantes para captar os efeitos da rigidez orçamentária nas decisões de política fiscal.

Os resultados das estimações GMM dos modelos estáticos e dinâmicos convergem para a constatação do comportamento pró-cíclico da política fiscal no período analisado. Como, em todos os casos analisados, encontrou-se uma relação positiva e estatisticamente significante entre hiato do produto e a razão gastos públicos sobre o PIB, então a condição de pró-ciclicidade da política fiscal foi satisfeita. Logo, em épocas de expansão econômica, o governo age elevando os gastos 
governamentais, corroborando as evidências empíricas obtidas por Rocha e Giuberti (2008), Mendonça, Medrano e Sachsida (2009), Rocha (2009) e Thomas (2010), os quais utilizaram metodologias e períodos distintos ao deste estudo.

Além disso, os resultados obtidos nesse estudo validam as teorias defendidas por Talvi e Vegh (2005), Alesina, Campante e Tabellini (2008) e Çicek e Elgin (2011). Em outras palavras, os argumentos sobre variabilidade da base tributária, corrupção e economia informal contribuem para explicar a natureza pró-cíclica da política fiscal brasileira. Por outro lado, a teoria sobre restrição ao crédito internacional defendida por Gavin e Perotti (1997a,b) e Kaminsky, Reinhart e Vegh (2004) não encontra respaldo empírico no período analisado. Pelo contrário, o fluxo de capitais internacionais é anticíclico e contribui para reduzir o comportamento pró-cíclico dos gastos governamentais.

Analisando-se a magnitude e a significância do coeficiente de resposta do gasto público sobre o PIB em relação ao hiato do produto nas equações estáticas e dinâmicas estimadas, observa-se que não há consenso sobre qual teoria mais contribui para explicar a natureza pró-cíclica da política fiscal. Enquanto que as estimações estáticas (ver apêndice) apontam para a teoria da economia informal seguida pela teoria da variabilidade da base tributária, as estimações dinâmicas indicam a teoria da corrupção. Esse último resultado deve ser avaliado com bastante cautela, uma vez que o indicador de corrupção aqui utilizado não está imune a críticas e possui limitações, de modo que o canal em que a corrupção afeta o comportamento pró-cíclico da política fiscal no Brasil deve ser analisado com maior profundidade em pesquisas futuras que devam utilizar outro indicador de corrupção mais robusto e de metodologia consistente e apropriada.

Os resultados indicam que as decisões de política fiscal são influenciadas pelo comportamento passado do gasto governamental, haja vista o elevado nível de rigidez (inércia) orçamentária, que pode ser resultado de diversos fatores, por exemplo, a trajetória crescente das despesas obrigatórias (constitucionais e legais); a defasagem temporal devido ao longo processo político observado na tomada de decisões para se alterar a trajetória de gastos e de impostos; e o elevado volume de receitas vinculadas a despesas específicas, na medida em 
que estas receitas não podem ser utilizadas para financiar despesas diversas daquelas para as quais foram criadas.

No tocante a pesquisas futuras, sugere-se investigar a influência de fatores políticos e institucionais no comportamento cíclico da política fiscal no Brasil. Por um lado, Tornell e Lane (1999) introduzem a noção de "efeito voracidade", em que um choque positivo de renda leva ao aumento mais que proporcional no gasto público, mesmo que esse choque seja temporário. Este, por sua vez, é a consequência da estrutura de instituições fracas, bem como da presença de vários grupos poderosos e concorrentes no processo fiscal exercendo atividades rent-seeking. Por outro lado, Ilzetzki (2011) desenvolve um modelo dinâmico em que sucessivos governos discordam sobre a distribuição desejada da despesa pública, levando à adoção de políticas fiscais pró-cíclicas. Especificamente, o governo no poder enfrenta um trade-off entre o desejo de suavizar o consumo de seus constituintes (eleitores) e o medo de que os superávits orçamentários deixados para o governo sucessor irão beneficiar outros constituintes. Dessa forma, os gastos governamentais se tornam pró-cíclicos, à medida que o governo no poder prefere aumentar os gastos em períodos de prosperidade econômica, e dessa forma beneficiar seus eleitores, assim como evita deixar superávits orçamentários ao governo sucessor para que esse último não beneficie outros eleitores. 


\section{Apêndice}

Tabela 3 - Teorias sobre Política Fiscal Pró-Cíclica. Estimações GMM em Modelos Estáticos

\begin{tabular}{|c|c|c|c|c|c|}
\hline \multirow{2}{*}{$\begin{array}{l}\text { Variáveis } \\
\text { Explicativas }\end{array}$} & \multicolumn{5}{|c|}{ Variável Dependente: Gasto Governamental/PIB } \\
\hline & $\begin{array}{l}\text { Modelo } \\
\text { Básico }^{1}\end{array}$ & $\begin{array}{l}\text { Var. Base } \\
\text { Tributária }^{2}\end{array}$ & Corrupção ${ }^{3}$ & $\begin{array}{l}\text { Economia } \\
\text { Informal }^{4}\end{array}$ & $\begin{array}{c}\text { Liquidez } \\
\text { Internacional }^{5}\end{array}$ \\
\hline Constante & $\begin{array}{c}1,1655^{\star \star \star} \\
(0,0000)\end{array}$ & $\begin{array}{c}0,6373^{* * *} \\
(0,0000)\end{array}$ & $\begin{array}{c}0,8245^{\star * *} \\
(0,0000)\end{array}$ & - & $\begin{array}{c}0,7252^{* * \star} \\
(0,0000)\end{array}$ \\
\hline$y_{t}^{c}$ & $\begin{array}{l}0,2326^{\star *} \\
(0,0537)\end{array}$ & $\begin{array}{l}0,0642^{\star \star} \\
(0,0165)\end{array}$ & $\begin{array}{l}0,0190^{* *} \\
(0,0225)\end{array}$ & $\begin{array}{c}0,1026^{\star * \star} \\
(0,0002)\end{array}$ & $\begin{array}{c}0,1836^{\star \star \star} \\
(0,0004)\end{array}$ \\
\hline dcrise $_{t}$ & $\begin{array}{c}0,0246^{\star * *} \\
(0,0003)\end{array}$ & $\begin{array}{c}0,0095^{\star \star \star} \\
(0,0000)\end{array}$ & $\begin{array}{c}0,0077^{\star \star \star} \\
(0,0000)\end{array}$ & $\begin{array}{c}0,0108^{\star \star *} \\
(0,0000)\end{array}$ & $\begin{array}{c}0,0144^{\star \star \star} \\
(0,0000)\end{array}$ \\
\hline$\tau_{t}$ & - & $\begin{array}{c}0,1672^{\star \star \star} \\
(0,0000)\end{array}$ & - & - & - \\
\hline desemp $p_{t}$ & - & $\begin{array}{c}-0,0021^{\star * \star} \\
(0,0000)\end{array}$ & $\begin{array}{c}-0,0026^{\star * *} \\
(0,0000)\end{array}$ & - & $\begin{array}{c}-0,0022^{* \star *} \\
(0,0030)\end{array}$ \\
\hline$(P M P P / D V B C)_{t}$ & - & $\begin{array}{c}0,5416^{\star \star \star} \\
(0,0000)\end{array}$ & - & $\begin{array}{c}0,8091^{\star * \star} \\
(0,0000)\end{array}$ & $\begin{array}{c}0,5572^{\star \star *} \\
(0,0001)\end{array}$ \\
\hline corrup $_{t}$ & - & - & $\begin{array}{c}0,3368^{\star \star \star} \\
(0,0000)\end{array}$ & - & - \\
\hline autônomo ${ }_{t}$ & - & - & - & $\begin{array}{c}0,0472^{\star \star *} \\
(0,0000)\end{array}$ & - \\
\hline$f d i_{t}$ & - & - & - & - & $\begin{array}{c}-0,0703^{\star \star *} \\
(0,0030)\end{array}$ \\
\hline Hansen-Sargan & $\begin{array}{c}0,0813 \\
(0,7754)\end{array}$ & $\begin{array}{c}0,9853 \\
(0,3209)\end{array}$ & $\begin{array}{c}1,1898 \\
(0,2753)\end{array}$ & $\begin{array}{c}4,4006 \\
(0,1108)\end{array}$ & $\begin{array}{c}2,2431 \\
(0,1342)\end{array}$ \\
\hline
\end{tabular}

Notas: ${ }^{* *}$ - significância a $1 \%$; ${ }^{* *}$ - significância a 5\%; * - significância a $10 \%$. Os termos entre parênteses são os valores-p.

1- Estimação da matriz de ponderação: HAC (lags $=1$, Bartlett Kernel, Bandwidth NeweyWest fixado $=5,0000)$. Instrumentos utilizados (4): constante, $y_{t-2}^{c}, y_{t-3}^{c}$ e dcrise $e_{\text {. }}$.

2- Estimação da matriz de ponderação: HAC (lags $=11$, Bartlett Kernel, Bandwidth NeweyWest fixado $=5,0000)$. Instrumentos utilizados (7): constante, $y_{t-1}^{c}, \tau_{t}, \tau_{t-1}$, desempt $(P M P P / D V B C)_{t-1}$, e dcrise . $_{\text {. }}$

3- Estimação da matriz de ponderação: HAC (lags $=15$, Bartlett Kernel, Bandwidth NeweyWest fixado $=5,0000)$. Instrumentos utilizados (6): constante, $y_{t-1}^{c}$, corrup $p_{t}$ corrup $p_{t-1}$, desemp $_{t}$, dcrise . $_{\text {. }}$

4- Estimação da matriz de ponderação: HAC (lags = 11, Bartlett Kernel, Bandwidth Newey-West fixado $=5,0000)$. Instrumentos utilizados $(6): y_{t-1}^{c},(P M P P / D V B C)_{t}(P M P P / D V B C)_{t-1}$, autônomo $_{t}$, autônomo $t$ - 1 , dcrise . $_{\text {. }}$.

5- Estimação da matriz de ponderação: HAC (lags $=6$, Bartlett Kernel, Bandwidth NeweyWest fixado $=5,0000)$. Instrumentos utilizados (7): constante, e $y_{t-2}^{c}, f d i_{t}, f d i_{t-1},(P M P P /$ DVBC) $)_{t-1}$, desempt-1 $e$ dcrise . $_{\text {. }}$ 


\section{Referências}

AKITOBY, B.; CleMENTS, B.; GUPTA, S.; INCHAUSTE, G. Public spending, voracity, and Wagner's law in developing countries. European Journal of Political Economy, v. 22, p. 908-924, 2006.

ALESINA, A.; CAMPANTE, F. R.; TABELLINI, G. R. Why is fiscal policy often procyclical? Journal of European Economic Association, v. 6, n. 5, p. 1006-1030, 2008.

BAXTER, M.; KING, R. G. Measuring business cycles: approximate band-pass filters for economic time series. NBER Working Paper n. 5.022, Cambridge, 1995.

BEN SLIMANE, S.; BEN TAHAR, M. Why is fiscal policy procyclical in MENA countries? International Journal of Economics and Finance, v. 2, n. 5, p. 44-53, 2010.

BOGDANSKI, J.; FREITAS, P. S.; GOLDFAJN, I.; TOMBINI, A. A. Inflation targeting in Brazil: shocks, backward looking prices and IMF conditionality. Banco Central do Brasil Working Paper Series, n. 24, 2001. Disponível em: $<<$ http://www.bcb.gov.br/pec/wps/ingl/wps24.pdf >>. Acesso em: 27 de dez. 2011.

BRASIL. Mercado de trabalho: conjuntura e análise. Instituto de Pesquisa Econômica Aplicada, ano 16, maio 2011.

ÇIÇEK, D.; ELGIN, C. Cyclicality of fiscal policy and the shadow economy. Empirical Economics, v. 41, p. 725737, 2011

CUSINATO, R. T.; MINELLA, A.; PÔRTO JÚNIOR, S. S. Produção Industrial no Brasil: uma análise de dados em tempo real. Banco Central do Brasil Working Paper Series, n. 209, 2010. Disponível em: $<<$ http://www.bcb. gov.br/pec/wps/port/wps209.pdf $>$ >. Acesso em: 05 de jun. 2012.

DICKEY, D. A. e FULLER, W.A. Distribution of the estimators for autoregressive time series with unit root. Journal of the American Statistical Association, v. 74, n. 336, p. 427-431, 1979.

Likelihood ratio statistics for auto-regressive time series with unit root. Econometrica, v. 49, n 4, 1981.

DI TELLA, R.; SCHARGRODSKY, E. Global Corruption Report. In: Transparency International, 2003.

ELLERY, R.; GOMES, V.; SACHSIDA, A. Business cycle fluctuations in Brazil. Revista Brasileira de Economia, v. 56, n. 2, p. 269-308, 2002.

ELLIOT, G., ROTHENBERG, T. J. e STOCK, J. H. Efficient tests for an autoregressive unit root. Econometrica, v. 64, n. 4, p. 813-836, 1996.

ERBIL, N. Is fiscal policy procyclical in developing oil-producing countries? IMF Working Paper n. 171, julho de 2011.

FATAS, A.; MIHOV, I. Fiscal policy and business cycles: an empirical investigation. Moneda y Credito, n. 211, 2001.

GALI, J. Modern perspective of fiscal stabilization policies. CESifo Economic Studies, v. 51, n. 4, p. 587-599, 2005.

GALI, J.; PEROTTI, R. Fiscal policy and monetary integration in Europe. Economic Policy, v. 18, n. 37, p. 533-572, 2003.

GAVIN, M.; PEROTTI, R. Fiscal policy in Latin America. In: BERNANKE, B.; ROTEMBERG, J. (Eds.). NBER Macroeconomics Annual, MIT Press, Cambridge, v. 12, p. 11-61, 1997a.

. Fiscal policy and saving in good times and bad times. In: Hausmann, R., Reisen, H. (Eds.), Promoting Savings in Latin America, IDB and OECD, 1997b.

GIAMBIAGI, F. 18 anos de política fiscal no Brasil: 1991/2008. Economia Aplicada, São Paulo, v. 12, n. 4, p. 535580, outubro-dezembro, 2008.

HAMILTON, J. D. Time series analysis. New Jersey: Princeton University Press, 1994.

HANSEN, L. P. Large sample properties of generalized methods of moments estimators. Econometrica, v. 50, p. 1029-1054, 1982.

HODRICK, R. J.; PRESCOTT, E. C. Postwar U.S. business cycles: an empirical investigation. Journal of Money, Credit, and Banking, 29 (1), p. 1-16, 1997.

ILZETZKI, E. Rent-seeking distortions and fiscal procyclicality. Journal of Development Economics, v. 96, p. 30-46, 2011.

KAMINSKY, G.; REINHART, C.; VEGH, C. A. When it rains, it pours: procyclical capital flows and macroeconomic policies. NBER Working Paper n. 10780, 2004.

Estud. Econ., São Paulo, vol. 43, n.4, p. 711-743, out.-dez. 2013 
KING, R. G.; REBELO, S. T. Transitional dynamics and economic growth in the neoclassical model. American Economic Review, v. 83, n. 4, p. 908-931, 1993.

LANE, P. R. The cyclical behaviour of fiscal policy: evidence from the OECD. Journal of Public Economics, v. 87, p. $2661-2675,2003$.

LANNE, M; SAIKKONEN, P; LÜTKEPOHL, H. Comparison of unit root tests for time series with level shifts. Journal of Time Series Analysis, 23, pp. 667-685, 2002.

. Test procedures for unit roots in time series with level shifts at unknown time. Oxford Bulletin of Economics and Statistics, v. 65, p. 91-115, 2003.

LIMA, F. T. Relação dos salários como proxy de corrupção: os efeitos sobre as despesas de governos subnacionais no Brasil (1992-1998). 2004. 209 f. Mestrado em Administração Pública e Governo (Dissertação) - Escola de Administração de Empresas de São Paulo, Fundação Getúlio Vargas, 2004.

LUCAS Jr., R. E.; STOKEY, N. Optimal fiscal and monetary policy in an economy without capital. Journal of Monetary Economics, v. 12, p. 55-93, 1983.

MACIEL, F. G. O controle da corrupção no Brasil. Brasília, 2005. 48 f. I Concurso de Monografias e Redações da Controladoria-Geral da União (CGU). Brasília, 2005.

MAURO, P. Corruption: causes, consequences, and agenda for further research. Finance and Development. Washington, D. C., v. 35, n. 1, p. 11-14, março de 1998.

MENDONÇA, M. J.; MEDRANO, L. A.; SACHSIDA, A. Avaliando os efeitos da política fiscal no Brasil: resultados de um procedimento de identificação agnóstica. Instituto de Pesquisa Econômica Aplicada (Ipea), Texto para Discussão $n^{\circ}$ 1377, 2009.

NG, S. e PERRON, P. Lag length selection and the construction of unit root tests with good size and power. Econometrica, v. 69, n. 6, p. 1519-1554, 2001.

PERRON, P. The great crash, the oil price shock, and the unit root hypothesis. Econometrica, v. 57, n. 6. p. 1361$1401,1989$.

PHILLIPS, P. C. B. e PERRON, P. Testing for unit root in time series regression. Biometrika, v. 75, n. 2, p. 335-346, 1988.

ROCA, J. C. C.; MORENO, D. C.; SANCHEZ, J. E. G. Underground economy and aggregate fluctuations. Spanish Economic Review, v. 3, p. 41-53, 2003.

ROCHA, F.; GIUBERTI, A.C. Assimetria cíclica na política fiscal dos estados brasileiros. Pesquisa e Planejamento Econômico, v. 38, n. 2, 2008.

ROCHA, F. Política fiscal através do ciclo e operação dos estabilizadores fiscais. Revista Economia, v. 10, n. 3, p. 483-499, set/dez 2009.

SAID, S. e DICKEY, D. A. Testing for unit roots in autoregressive-moving average models of unknown order. Biometrika, v. 71, p. 599-607, 1984.

SAIKKONEN, P; LÜTKEPOHL, H. Testing for a unit root in a time series with a level shift at unknown time. Econometric Theory, v. 18, p. 313-348, 2002.

STRAWCZYNSKI, M.; ZEIRA, J. Procyclicality of fiscal policy in emerging countries: the cycle is the trend. Central Bank of Chile Working Paper $n^{\circ}$ 624, maio 2011.

TALVI, E.; VEGH, C. A. Tax base variability and procyclical fiscal policy. Journal of Development Economics, v. 78, p. 156-190, 2005.

TIRYAKI, G. F. A informalidade e as flutuações na atividade econômica. Estudos Econômicos, São Paulo, v. 38, n. 1, p. 97-125, janeiro-março, 2008.

TORNELL, A.; LANE, P. R. The voracity effect. American Economic Review, v. 89, p. 22-46, 1999.

THOMAS, W. A. P. A politica fiscal influencia a politica monetária no Brasil? Uma abordagem sob o ciclo de negócios. 2010. 40 f. Dissertação (Mestrado em Economia) - Programa de Pós-Graduação em Economia Aplicada da Faculdade de Economia, Administração e Contabilidade de Ribeirão Preto da Universidade de São Paulo, Ribeirão Preto, 2010. 
THORNTON, J. Explaining procyclical fiscal policy in African Countries. Journal of African Economies, v. 17, n. 3, p. 451-464, 2008.

VAN RIJCKEGHEM, C.; WEDER, B. Corruption and rate of temptation: do low wages in the civil service cause corruption? IMF Working Paper n. 73/97. Washington, D.C.: International Monetary Fund, 1997.

VEGH, C. A.; VULETIN, G. How is tax policy conducted over the business cycle? NBER Working Paper Series $\mathrm{n}$. 17753, Cambridge, 2012.

WAGNER, A. Der Staat in nationalokonomischer Hinsicht. In: Conrad, Johannes, et. al. (Ed.), Handworterbuch der Staatswissenschaften, third edition completely revised, v. 7, p. 743-745, Jena: Lexis, 1911. 